\title{
The effect of preoperative warming on perioperative hypothermia in transurethral prostatectomies
}

\author{
(i) Fatma Kavak Akelma, (1) Jülide Ergil, (1) Derya Özkan, (1) Emine Arık, (1) İlkay Baran Akkuş, \\ (1) Gözde Bumin Aydın
}

University of Health Sciences Turkey, Diskapi Yildirim Beyazit Training and Research Hospital, Clinic of Anesthesiology and Reanimation, Ankara, Turkey

Date submitted:

10.01.2020

Date accepted:

30.01.2020

Online publication date:

15.06.2020

\section{Corresponding Author:}

Fatma Kavak Akelma MD, University of Health Sciences Turkey, Diskapi

Yildirim Beyazit Training and Research Hospital, Clinic of Anesthesiology and Reanimation, Ankara, Turkey

fatmakavak@yahoo.com

ORCID:

orcid.org/0000-0003-3647-7516

Presented in: 53th National Congress of Turkish Anesthesiology and Reanimation Society TARK 2019.

Keywords: TURP, hypothermia, hemodynamic variable, prewarming

\begin{abstract}
Aims: The aim of this study was to assess the effectiveness of warming in perioperative hypothermia, hemodynamic variables, post-anesthesia care unit discharge time, shivering, patient comfort and patient satisfaction in elderly patients undergoing transurethral resection of prostate (TURP) surgery under general anesthesia.
\end{abstract}

Methods: Patients aged between 50 and 85 years, scheduled for TURP surgery of 30-90 min under general anesthesia, were enrolled into the study. Patients were randomly allocated to either the warming (Group P) or standard care (Group C) group. Core body temperatures and hemodynamic parameters were assessed. Additionally, patient satisfaction, thermal comfort, and shivering were compared using scales.

Results: Overall, 33 patients (Group P; $n=16$, Group C; $n=17$ ) completed the study. Core body temperature was higher in Group P after anesthesia induction than in Group C (37.01 \pm 0.29 vs $36.61 \pm 0.21)(p=0.001)$. In addition, at the end of surgery, the core temperature was significantly higher in Group P $(36.03 \pm 0.33)$ than in Group C $(35.31 \pm 0.45)(p=0.001)$. Hypothermia was observed in four warmed and 17 unwarmed patients at the end of surgery $(p=0.001)$. Following anesthesia induction, one warmed patient and nine unwarmed patients developed hypotension $(p=0.004)$. Thermal comfort and patient satisfaction scores were significantly higher in warmed patients than in unwarmed patients $(p<0.05)$, but shivering scores displayed a similar pattern between the groups ( $p>0.05)$.

Conclusions: This study demonstrated that perioperative forced-air warming helped preserve perioperative core body temperature, reduced the incidence of hypotension during the induction period, increased thermal comfort, improved patient satisfaction, but did not affect shivering in patients undergoing TURP surgery.

\section{Introduction}

Core body temperature is tightly regulated by thermoregulatory defense mechanisms such as sweating, shivering and arteriovenous shunt vasoconstriction. Perioperative hypothermia is defined as a core body temperature less than $36{ }^{\circ} \mathrm{C}$ during surgery and the postoperative period $(1,2)$. General anesthetics represent one of the most common cause of perioperative hypothermia. They impair several thermoregulatory defenses such as vasoconstriction and shivering and lead to thermal redistribution (3).
Perioperative hypothermia is associated with several complications such as coagulopathy (4), increased transfusion requirement (5), shivering (6), thermal discomfort (2), delayed drug metabolism (7), increased risk of surgical site infection (3), tissue ischemia (8), and delayed wound healing. Additionally, it may reduce patient satisfaction, prolong length of hospital stay, and increase hospital costs (1). Perioperative hypothermia is more accentuated in the elderly population undergoing transurethral resection of prostate (TURP) surgery in part due to the excessive use of irrigation fluids and in part due to their reduced thermoregulatory capacity (9). 
Cutaneous blood flow is influenced by both thermoregulation and cardiovascular homeostasis which are closely related to each other (10). Increased body temperature and accompanying vasodilation are followed by a moderate decrease in the central venous pressure and a passive redistribution of the blood flow towards the cutaneous vascular beds (10). During hypothermia, in contrast, circulating blood volume is reduced as a result of cutaneous vasoconstriction (4). Perioperative warming of the patient, in this regard, is an effective means of preserving thermal homeostasis (3) and inhibiting the hypotensive response. Warming the patient prior to anesthesia induction reduces redistribution hypothermia by increasing the temperature of peripheral tissues and lowering the core to periphery temperature gradient $(4,11)$. Among others, forced-air warming system is the most commonly used perioperative (pre-, intra- and post-operative) warming modality (12).

The primary aim of this study was to assess the effectiveness of prewarming on perioperative hypothermia in elderly patients undergoing TURP surgery under general anesthesia. We also sought to evaluate the effects of prewarming on hemodynamic variables, post-anesthesia care unit (PACU) discharge time, shivering, patient comfort and satisfaction.

\section{Methods}

We conducted a single-center, prospective, randomized, single-blinded (assessor-blinded) study at the Training and Research Hospital between November 2018 and February 2019. The trial was approved by the Ethical Committee of the Ministry of Health Diskapi Yildirim Beyazit Training and Research Hospital in Ankara, Turkey (protocol number: 06/22, date: 17.12.2012). It was registered at www.clinicaltrials.gov (NCT01858727). All patients gave their written informed consent to participate in the study.

American Anesthesiology Association (ASA) I-III patients aged between 50 and 85 years, with a body mass index (BMI) between 15 and $36 \mathrm{~kg} / \mathrm{m}^{2}$, scheduled for TURP surgery of 3090 min under general anesthesia, were enrolled in the study. Exclusion criteria were as follows: inadequate comprehension of the Turkish language, known impaired thermoregulation or thyroid disorders, presence of severe hypertension defined as a systolic blood pressure (SBP) $>180 \mathrm{mmHg}$ or diastolic blood pressure (DBP) $>110 \mathrm{mmHg}$ measured in the operating room, presence of secondary hypertension (e.g., Cushing's syndrome, pheochromocytoma, renal artery stenosis), presence of a vascular disease or poor cutaneous perfusion, presence of serious skin lesions, use of an angiotensin-converting enzyme inhibitor/angiotensin II receptor antagonist on the day of surgery, and a baseline temperature $\geq 37.5^{\circ} \mathrm{C}$. Preoperative visits were conducted by an anesthesiologist. Patients were randomly assigned to either the prewarming (Group $\mathrm{P}$ ) or standard care group (Group C) using a computer-generated list.
Patients were instructed on the use of the shivering scale ( $0=$ No shivering; $1=$ One or more of piloerection; peripheral cyanosis without other cause but without visible muscular activity; 2=Visible muscular activity confined to one muscle group; $3=$ Visible muscular activity in more than one muscle group; 4=Gross muscular activity involving entire body) (13), the patient satisfaction scale (Likert scale; range: 1-7), the 100-mm visual analog scale $(0 \mathrm{~mm}=$ Unbearably cold, $50 \mathrm{~mm}=$ Neutral, and $100 \mathrm{~mm}=$ Unbearably hot) to measure thermal comfort (14). Patients in the control group were given standard care without active warming in the admission and preoperative period. Patients in the prewarming group received 30 minutes of fullbody preoperative warm-up by nurses unaware of the study using a forced-air warming device (Mistral-Air/The 37 Company, Amersfoort, the Netherlands) set to $43^{\circ} \mathrm{C}$ in the preoperative waiting area, before entering the operating room. Patients were assessed every 5 minutes and the temperature was lowered to $37^{\circ} \mathrm{C}$ if the patient reported discomfort (2). Hemodynamic data and core body temperature were measured and recorded at baseline and at 30th min using the zero-heat-flux thermometry sensor (3M SpotOn, St. Paul, Minnesota, USA) placed on the patients' forehead (15). The researcher stayed in the operating room and did not reach the waiting area before surgery to ensure blindness. Patients were monitored during heating for undesirable effects such as vomiting, nausea, and diaphoresis.

Each patient received an infusion of $0.9 \%$ saline at 100 $\mathrm{mLhr}^{-1}$. To ensure blinding, the assessor remained in the surgery room and did not enter the preoperative waiting area. A protocol deviation was defined as a delay of 20 minutes or more between the end of warming and transfer to the surgery room. During surgery, potential warming-related adverse effects such as diaphoresis or nausea and vomiting were recorded. Premedication was not applied to the patients.

Heart rate (HR), SBP, DBP, mean arterial pressure (MAP), peripheral oxygen saturation, bispectral index (BIS, Quatro sensor and BIS VISTA monitor), room temperature and core body temperature were monitored and recorded every 15 minutes during surgery, at $0^{\text {th }}$ and $20^{\text {th }}$ min in the PACU and at 1 st, $2^{\text {nd }}$ and $12^{\text {th }}$ hours in the ward by a blinded investigator using noninvasive methods. Induction of anesthesia was achieved using infusions of propofol ( $4 \mu \mathrm{g} \cdot \mathrm{mL}^{-1}$ target effect-site concentration using the model of Schnider et al. (16) and by maintaining the BIS in the range 40-60. The attending anesthesiologist increased the concentration of propofol in increments of $1 \mu \mathrm{g} \cdot \mathrm{mL}^{-1}$ if the target BIS range was not reached within two minutes. The patient was intubated following neuromuscular blockade with rocuronium $0.6 \mathrm{mg} \cdot \mathrm{kg}^{-1} \mathrm{iv}$. Propofol was titrated using a target-controlled infusion adjusted for BIS between 40 and 60 . The dose of remifentanil was titrated according to the systemic blood pressure response during anesthesia care. If SBP declined more than $30 \%$ from the baseline value or if MAP 
was lower than $60 \mathrm{~mm} \mathrm{Hg}$, repeated doses of ephedrine $5 \mathrm{mg}$ iv were administered. If the HR fell below 45 beat/min, atropine was administered. Patients were positioned similarly during the entire surgical procedure and were transferred to the PACU by using a warmed cotton blanket and a reflective foil blanket following surgery. Forced-air warming continued in the PACU (1).

The shivering scale, patient satisfaction scale and the $100-\mathrm{mm}$ visual analog scale to measure thermal comfort were administered and recorded at $0^{\text {th }}$ and $20^{\text {th }}$ min in the PACU and at 1 st, $2^{\text {nd }}$ and $12^{\text {th }}$ hours in the ward by a blinded investigator. When the Modified Aldrett score was higher than 9 and the core body temperature was higher than $36^{\circ} \mathrm{C}$, the patient was discharged from the PACU. The time in PACU was recorded.

For analgesia, $50 \mathrm{mg}$ dexketoprofen trometamol was applied at the beginning of surgery and $100 \mathrm{mg}$ tramadol was intravenously administered towards the end of the surgery. For postoperative pain, intravenous $50 \mathrm{mg}$ dexketoprofen trometamol was administered every 8 hours. Patients with a numerical rating scale score of 4 or more received $50 \mathrm{mg}$ intravenous tramadol $\mathrm{HCl}$. Patients with severe postoperative nausea and vomiting (PONV) were given i.v. $10 \mathrm{mg}$ of metoclopramide. In addition to patients whose PONV complaints continued, i.v. ondansetron 4 mg was administered.

\section{Statistical Analysis}

Sample size was calculated based on an expected treatment effect of $0.5^{\circ} \mathrm{C}$ at the end of surgery, which has been shown to be the smallest difference associated with hypothermia induced complications (17). Using $\alpha$-error $=0.05$ at $80 \%$ power, we calculated the number of patients required per group as 16 and included 18 patients in each group considering potential dropouts.

Statistical Package for Social Sciences (SPSS) software version 24 was utilized for all other data analyses (SPSS, Inc., Chicago, IL, USA). Normality of continuous data was assessed using the one sample Kolmogorov-Smirnov test. Categorical data were summarized using number (percent), normally distributed data were presented using mean (standard deviation) and skewed data were summarized using median (interquartile range). Two group comparisons were conducted using the chisquare or Fisher's exact tests for categorical data, unpaired two-tailed Student's t-tests for normally distributed data and rank-sum tests for skewed data. Repeated measures analysis of variance was used to evaluate time-dependent changes in temperatures and hemodynamic values. A p value of $<0.05$ was considered to be statistically significant.

\section{Results}

A total of 42 patients were assessed for eligibility. Six of these were excluded as one had a thyroid disorder, three had severe hypertension, one used an angiotensin-converting enzyme inhibitor/angiotensin 2 receptor antagonist on the day of surgery, one had inadequate comprehension of the Turkish language. Overall 36 patients were included in the study. One patient in Group P and two in Group $\mathrm{C}$ were excluded because the duration of surgery was less than $30 \mathrm{~min}$. Consequently 33 patients (Group P; n=16, Group C; n=17) completed the study. Groups were well matched with regards to age, gender, BMI, ASA classification, room temperature, amount of irrigation fluid and intravenous fluid consumption ( $p>0.05$ ) (Table 1). Total rate of propofol consumption was also similar between the groups $(p=0.059)$ (Table 1).

Baseline core body temperature was similar between Group P and Group C ( $p=0.122)$. Core body temperature was significantly higher in warmed patients than in unwarmed patients after prewarming and at $0^{\text {th }}, 15^{\text {th }}, 30^{\text {th }}, 45^{\text {th }}, 60^{\text {th }}$ min after the induction of anesthesia and at the end of surgery $(p=0.001$, $p=0.001, \quad p=0.014, \quad p=0.001, p=0.001, \quad p=0.001, \quad p=0.001$ respectively) (Table 2) (Figure 1). Core body temperature was also significantly higher in warmed patients at postoperative $0^{\text {th }}$ and $20^{\text {th }} \min (p=0.039, p=0.01$ respectively), but remained similar between the groups at postoperative 1 st, $2^{\text {nd }}$ and $12^{\text {th }}$ hours ( $p=0.093, p=0.441, p=0.122$ respectively) (Figure 1 ). Hypothermia was observed in none of the warmed patients and in four unwarmed patients at $15^{\text {th }}$ min after anesthesia induction $(p=0.335)$; in two warmed and six unwarmed patients at 30th $\min (p=0.225)$; in three warmed and 17 unwarmed at $45^{\text {th }}$ min $(p=0.001)$; and in four warmed and 17 unwarmed patients at the end of surgery $(p=0.001)$. Operation time and baseline core body temperature values were similar between the groups $(p>0.05)$ (Table 1). PACU discharge time was shorter in warmed than in

\begin{tabular}{|c|c|c|}
\hline \multicolumn{3}{|c|}{$\begin{array}{l}\text { Table 1. Comparing prewarmed } \\
\text { demographics and operation factors }\end{array}$} \\
\hline & $\begin{array}{l}\text { Group P } \\
(n=16)\end{array}$ & $\begin{array}{l}\text { Group C } \\
(n=17)\end{array}$ \\
\hline Age (year) & $66.12(6.92)$ & $67.12(5.81)$ \\
\hline ASA (I/II/III) & $4 / 8 / 4$ & $3 / 11 / 3$ \\
\hline BMI $\left(\mathrm{kg} / \mathrm{m}^{2}\right)$ & $27.58(3.62)$ & $28.86(2.03)$ \\
\hline $\begin{array}{l}\text { Ambient room temperature } \\
\left({ }^{\circ} \mathrm{C}\right)\end{array}$ & $21.25(1.00)$ & 21.35 (1.05) \\
\hline Washing fluid (mL) & $8437(8545)$ & $8070(6007)$ \\
\hline IV fluid (mL) & $750(274)$ & $705(185)$ \\
\hline $\begin{array}{l}\text { Total propofol consumption } \\
\text { (mg) }\end{array}$ & $656(135.09)^{*}$ & 577 (94.96) \\
\hline Operation time (minute) & $52.25(12.87)$ & $58.23(16.29)$ \\
\hline PACU time (minute) & $31.18(9.57)^{* *}$ & $45.64(17.11)$ \\
\hline \multicolumn{3}{|c|}{$\begin{array}{l}\text { Values are presented as mean (standard deviation), or median (first-third } \\
\text { quartiles). } \\
\left.{ }^{*} p \text { value compared to the control group ( } p=0.059\right) \text {. } \\
{ }^{*} \text { Significant compared to the control group }(p=0.05) \text {. } \\
\text { PACU: Postanesthesia care unit, IV: Intravenous, BMI: Body mass index, ASA: } \\
\text { American Anesthesiology Association }\end{array}$} \\
\hline
\end{tabular}


unwarmed patients $(p=0.006)$ (Table 1$)$. Side effects such as diaphoresis or vomiting during the prewarming intervention were not seen in any patient.

Hemodynamic variables (mean SBP, DBP, HR levels) were similar between the groups at baseline $(p>0.05)$. Following warming, they were significantly reduced in warmed patients $(p=0.001)$, but remained unchanged in unwarmed patients $(p>0.05)$ and were significantly lower in warmed patients than in unwarmed patients $(p=0.01)$ (Table 3$)$. Following anesthesia induction, hemodynamic variables remained unchanged in warmed patients, but were significantly reduced in unwarmed patients $(p=0.001)$, and remained similar between the two groups ( $p>0.05)$. Following anesthesia induction, one warmed patient and nine unwarmed patients developed hypotension (Table 3). Hemodynamic variables showed a similar pattern between the two groups during the rest of the follow-up period $(p>0.05)$ (Table 3).

Thermal comfort and patient satisfaction scores were significantly higher in warmed patients than in unwarmed

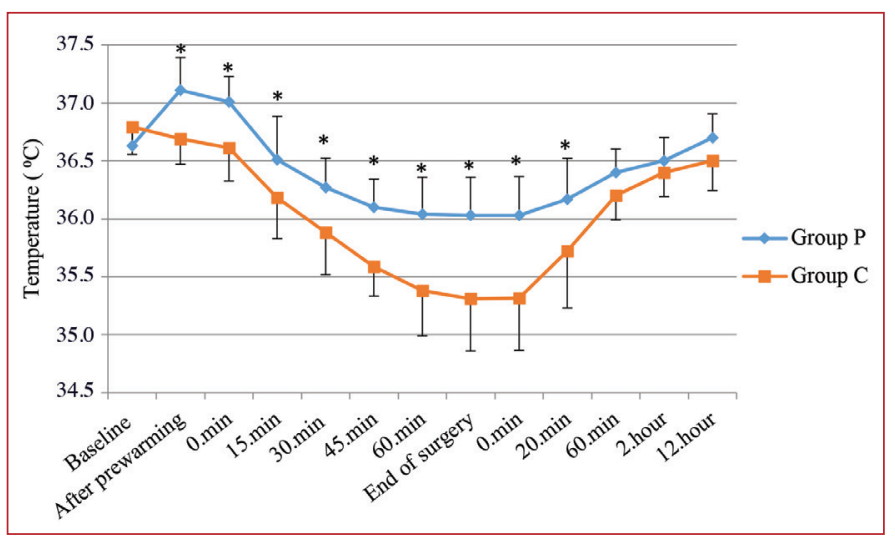

Figure 1. Mean perioperative core temperatures of the control Group C and the prewarming Group $P$

${ }^{*} p<0.05$ compared to Group C

\begin{tabular}{|c|c|c|c|}
\hline & $\begin{array}{l}\text { Group P } \\
(n=16)\end{array}$ & $\begin{array}{l}\text { Group C } \\
(n=17)\end{array}$ & $\begin{array}{l}p \\
\text { value }\end{array}$ \\
\hline Baseline $\left({ }^{\circ} \mathrm{C}\right)$ & $36.63(0.16)$ & $36.79(0.23)$ & 0.122 \\
\hline After prewarming $\left({ }^{\circ} \mathrm{C}\right)$ & $37.11(0.22)$ & $36.68(0.28)$ & 0.001 \\
\hline $\begin{array}{l}\text { After induction of } \\
\text { anesthesia }\left({ }^{\circ} \mathrm{C}\right)\end{array}$ & $37.01(0.29)$ & $36.61(0.21)$ & 0.001 \\
\hline $\begin{array}{l}15 \text { minutes after } \\
\text { induction of } \\
\text { anesthesia }\left({ }^{\circ} \mathrm{C}\right)\end{array}$ & $36.51(0.37)$ & $36.18(0.35)$ & 0.014 \\
\hline End of surgery $\left({ }^{\circ} \mathrm{C}\right)$ & $36.03(0.33)$ & $35.31(0.45)$ & 0.001 \\
\hline $\begin{array}{l}\text { Hypothermia in end of } \\
\text { surgery }(n / \%)\end{array}$ & $4 / 25$ & $17 / 100$ & 0.001 \\
\hline $\begin{array}{l}\text { Values are presented as me } \\
\text { All temperatures are core te }\end{array}$ & $\begin{array}{l}\text { standard deviai } \\
\text { rature values }\end{array}$ & ), or numbers & ntage. \\
\hline
\end{tabular}

patients at postoperative $0^{\text {th }}$ and 20 th minutes $(p<0.05)$ but were similar at postoperative 1 st, $2^{\text {nd }}$ and $12^{\text {th }}$ hours $(p>0.05)$ (Table 4). Shivering scores displayed a similar pattern between the groups at all assessment points (Table 4).

\section{Discussion}

We found that warming patients during the perioperative period prevented temperature decrease in patients undergoing TURP surgery. We also observed that this intervention increased thermal comfort, improved patient satisfaction and prevented

\begin{tabular}{|c|c|c|c|}
\hline & $\begin{array}{l}\text { Group P } \\
(n=16)\end{array}$ & $\begin{array}{l}\text { Group C } \\
(n=17)\end{array}$ & $\begin{array}{l}\text { p value } \\
\text { (prewarming- } \\
\text { control) }\end{array}$ \\
\hline \multicolumn{4}{|l|}{ Baseline } \\
\hline $\mathrm{SBP}(\mathrm{mmHg})$ & $128(19)$ & $130(20)$ & 0.853 \\
\hline MAP (mmHg) & $96(16)$ & $99(16)$ & 0.576 \\
\hline HR (beats/min) & $76(9)$ & 75 (15) & 0.915 \\
\hline \multicolumn{4}{|l|}{ After prewarming } \\
\hline $\mathrm{SBP}(\mathrm{mmHg})$ & $106(5)^{\star}$ & $131(11)$ & 0.001 \\
\hline MAP $(\mathrm{mmHg})$ & $82(6)^{*}$ & $102(11)$ & 0.001 \\
\hline HR (beats/min) & $65(3)^{*}$ & $84(10)$ & 0.001 \\
\hline \multicolumn{4}{|l|}{ Post induction } \\
\hline $\mathrm{SBP}(\mathrm{mmHg})$ & $103(7)$ & 102 & 0.136 \\
\hline MAP $(\mathrm{mmHg})$ & $78(9)$ & $(14)^{*}$ & 0.570 \\
\hline HR (beats/min) & $65(3)$ & $\begin{array}{l}71(15)^{* *} \\
70(8)^{\star *}\end{array}$ & 0.665 \\
\hline \multicolumn{4}{|l|}{ 15.min } \\
\hline $\mathrm{SBP}(\mathrm{mmHg})$ & $95(15)$ & $98(17)$ & 0.526 \\
\hline $\mathrm{MAP}(\mathrm{mmHg})$ & 72 (18) & 75 (15) & 0.419 \\
\hline HR (beats/min) & $66(17)$ & $65(14)$ & 0.824 \\
\hline \multicolumn{4}{|l|}{$30 . \min$} \\
\hline $\mathrm{SBP}(\mathrm{mmHg})$ & $107(9)$ & $101(12)$ & 0.141 \\
\hline $\mathrm{MAP}(\mathrm{mmHg})$ & $81(8)$ & $76(13)$ & 0.149 \\
\hline HR (beats/min) & $65(9)$ & $73(14)$ & 0.074 \\
\hline \multicolumn{4}{|l|}{ 45.min } \\
\hline $\mathrm{SBP}(\mathrm{mmHg})$ & $116(6)$ & $108(12)$ & 0.092 \\
\hline $\mathrm{MAP}(\mathrm{mmHg})$ & $91(4)$ & $82(9)$ & 0.118 \\
\hline HR (beats/min) & $66(6)$ & $65(9)$ & 0.780 \\
\hline \multicolumn{4}{|l|}{ 60.min } \\
\hline $\mathrm{SBP}(\mathrm{mmHg})$ & $119(5)$ & $98(11)$ & 0.011 \\
\hline $\mathrm{MAP}(\mathrm{mmHg})$ & 74 (11) & $68(12)$ & 0.772 \\
\hline HR (beats/min) & $68(11)$ & $55(3)$ & 0.488 \\
\hline \multicolumn{4}{|l|}{ End of surgery } \\
\hline $\mathrm{SBP}(\mathrm{mmHg})$ & $115(15)$ & $102(17)$ & 0.062 \\
\hline $\mathrm{MAP}(\mathrm{mmHg})$ & $65(8)$ & $72(9)$ & 0.083 \\
\hline HR (beats/min) & $89(15)$ & $81(18)$ & 0.488 \\
\hline $\begin{array}{l}\text { Hypotension in post } \\
\text { induction }\end{array}$ & $1 / 6.25$ & $9 / 52.94$ & 0.004 \\
\hline \multicolumn{4}{|c|}{$\begin{array}{l}\text { Values are presented as mean (standard deviation), or numbers/percentage. } \\
\text { All temperatures are core temperature values. } \\
{ }^{*} p=0.001 \text { compared to the baseline value. } \\
{ }^{* *} p=0.001 \text { compared to the prewarming time value. } \\
\text { SBP: Systolic blood pressure, MAP: Mean arterial pressure, HR: Heart rate, } \\
\text { min: Minute }\end{array}$} \\
\hline
\end{tabular}


hypotension during anesthesia induction, but did not affect shivering.

Perioperative hypothermia is a common but almost always preventable complication of elective surgery. It is associated with poor clinical outcomes and serious medical complications such as myocardial ischemia, blood loss and surgical site infection (18). TURP patients mostly belong to the geriatric age group who already present with pulmonary and/or renal comorbidities and/or adverse cardiovascular events such as hypertension and tachyarrhythmia (19). The use of high volume irrigation fluids during TURP surgery and the presence of a reduced shivering threshold further increase the risk of perioperative hypothermia (20). Prevention of hypothermia and hemodynamic instability in the elderly is therefore critical. Warming increases peripheral tissue temperature and thereby reduces core to peripheral tissue temperature gradient, a process that reduces blood redistribution following anesthetic induction and that ameliorates redistribution hypothermia. Warming the patient is usually performed using the forced-air warming system (21).

Horn et al. (21) compared the effectiveness of preoperative warming versus usual care among women receiving general anesthesia and found that the number of patients who developed hypothermia was less in warmed patients. Munday et al. (1), in contrast, found no difference in the rate of hypothermia between women who did and did not receive preoperative warming before spinal anesthesia for cesarean delivery. In the current study, we found that warmed patients had higher mean perioperative core temperatures at each assessment point during the study period. Additionally, while hypothermia was observed as early as 15

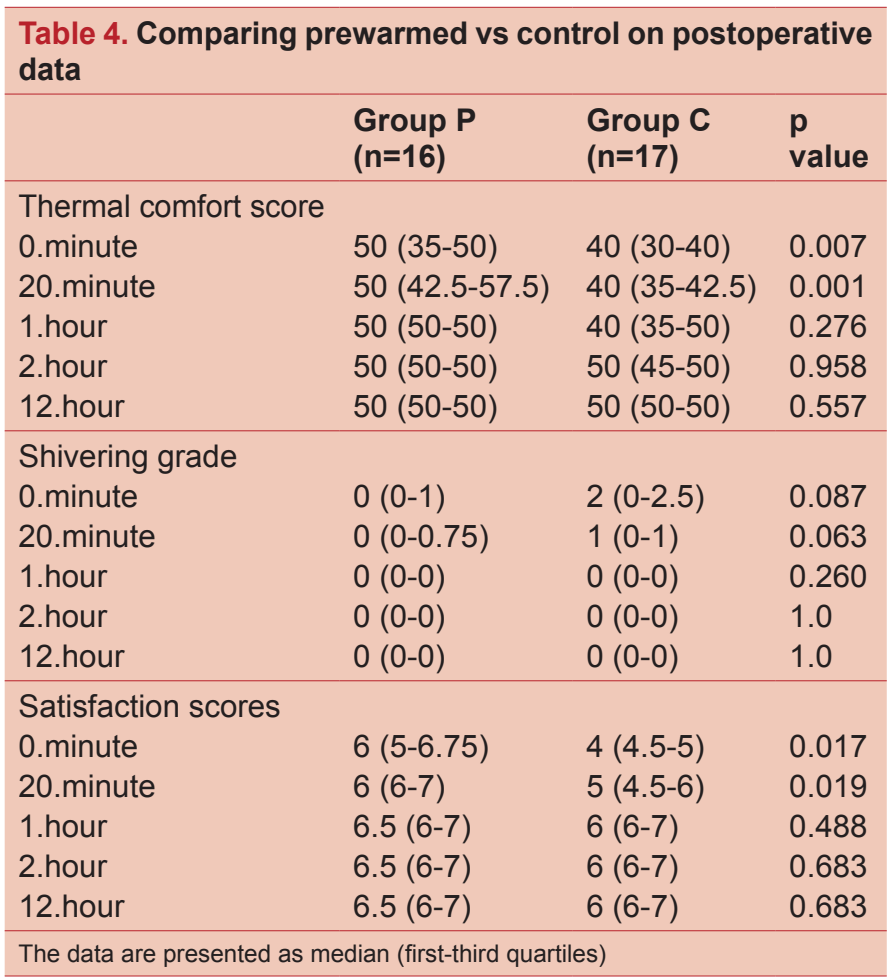

minutes after anesthetic induction in some unwarmed patients, it was observed only after 30 minutes in warmed patients. These discrepancies may be due to the differences in ambient temperature, variations in surgery duration and/or the use or non-use of intrathecal morphine.

Warming increases both peripheral tissue and core body temperatures. Increased cutaneous temperature facilitates the opening of vascular beds and indirectly increases cardiac output due to splanchnic vasoconstriction (10). Warming, in this regard, may help prevent anesthesia-mediated hypotension $(10,22)$. Kim et al. (23) assessed the effectiveness of cutaneous warming during anesthesia preparation on temperature and hemodynamic variables in the early operative period in patients undergoing off-pump coronary artery bypass surgery. They found that MAP values remained within the normal range at the pre-induction period in warmed patients but not in unwarmed patients. Darvall et al. (22) found no difference in MAP values both at the pre-and post-induction period between patients warmed with convective forced-air one hour prior to intravenous anesthetic induction and unwarmed patients. In the current study, warmed patients developed significantly less hypotension than unwarmed patients during the post-induction period $(6.25 \%$ vs $52.94 \%$ ) and MAP values were significantly lower in warmed patients $(4.87 \%$ vs. $30.39 \%)$.

The primary thermoregulatory defense mechanisms in humans are sweating, shivering and arteriovenous shunt vasoconstriction (4). The intensity of postoperative shivering may vary depending on the severity of intraoperative hypothermia (1). Postoperative shivering reduces patient satisfaction and comfort (2), and may augment oxygen consumption by increasing the metabolic rate by up to five folds (4). An augmentation in oxygen consumption may facilitate the development of cardiac complications such as arrhythmia, angina pectoris and myocardial infarction and may prolong the postoperative recovery time in the elderly patients who already present with comorbidities. While some studies claim that perioperative warming may prevent shivering (21), many others demonstrated that warming alone was insufficient $(1,11,18)$ because nonthermogenic factors such as pain or anxiety also contribute to the development of shivering through the release of catecholamines (24). In the current study, although the incidence of shivering was similar between the groups, thermal comfort scores and patient satisfaction scores were higher in warmed patients. This may be related to the warming process which not only provides the warming of the patient but also allows a more personalized care which usually provides some sort of psychological comfort.

TURP surgery may be conducted by either regional or general anesthesia. General anesthesia is preferred in the elderly as they may present with disorders such as vertebral collapse, osteophytes and calcified ligamentum flavum that complicate the application of a central nerve block. In the 
current study, we included only patients undergoing general anesthesia. It should therefore be noted that the effects of warming could differ in patients undergoing regional anesthesia because central nerve block application inhibits vasomotor and shivering responses and impairs autoregulation causing thermal redistribution from core to peripheral tissues (25). This dermatomal distribution may further increase the risk of intra- and post-operative hypothermia (26). Future studies that compare the effects of warming in patients undergoing regional or general anesthesia in TURP patients are warranted.

One limitation of this study is that, in control group patients, standard blankets, which are used in routine practice in many services, were used to provide passive warming. Another limitation is that after the prewarming application, cotton blankets were used in the transfer process (about 10 minutes) until the induction of anesthesia.

\section{Conclusion}

This study demonstrated that perioperative forced-air warming helped preserve perioperative core body temperature, reduced the incidence of hypotension during the induction period, increased thermal comfort, and improved satisfaction in patients undergoing TURP surgery. Warming may be recommended in patients undergoing TURP surgery.

\section{Ethics}

Ethics Committee Approval: The trial was approved by the Ethical Committee of the Ministry of Health Diskapi Yildirim Beyazit Training and Research Hospital in Ankara, Turkey (protocol number: 06/22, date: 17.12.2012).

Informed Consent: All patients gave their written informed consent to participate in the study.

Peer-review: Externally peer-reviewed.

\section{Authorship Contributions}

Surgical and Medical Practices: F.K.A., J.E., D.Ö., Concept: F.K.A., J.E., D.Ö., İ.B.A., Design: F.K.A., J.E., G.B.A., E.A., Data Collection or Processing: F.K.A., I.B.A., E.A., G.B.A, Analysis or Interpretation: F.K.A., D.Ö., J.E., E.A., G.B.A., Literature Search: D.Ö., G.B.A., İ.B.A. Writing: F.K.A., J.E., D.Ö., İ.B.A., E.A., G.B.A.

Conflict of Interest: No conflict of interest was declared by the authors.

Financial Disclosure: The authors declared that this study received no financial support.

\section{References}

1. Munday J, Osborne S, Yates P, Sturgess D, Jones L, Gosden E. Preoperative Warming Versus no Preoperative
Warming for Maintenance of Normothermia in Women Receiving Intrathecal Morphine for Cesarean Delivery: A Single-Blinded, Randomized Controlled Trial. Anesth Analg. 2018;126:183-189.

2. Akhtar Z, Hesler BD, Fiffick AN, et al. A randomized trial of prewarming on patient satisfaction and thermal comfort in outpatient surgery. J Clin Anesth. 2016;33:376-385.

3. KurzA, Sessler DI, Lenhardt R. Perioperative normothermia to reduce the incidence of surgical-wound infection and shorten hospitalization. Study of Wound Infection and Temperature Group. N Engl J Med. 1996;334:1209-1215.

4. Sessler DI. Perioperative thermoregulation and heat balance. Lancet. 2016;387(10038):2655-2664.

5. Rajagopalan S, Mascha E, Na J, Sessler DI. The effects of mild perioperative hypothermia on blood loss and transfusion requirement. Anesthesiology. 2008;108:71-77.

6. Baran İ, Okşar M, Altınsoy S. The Effect of Neuromuscular Agent on Postoperative Shivering in Patients Undergoing Retrograde Intrarenal Surgery: A Randomized Controlled Clinical Trial. JARSS 2019;27:51-55.

7. Heier T, Caldwell JE. Impact of hypothermia on the response to neuromuscular blocking drugs. Anesthesiology. 2006;104:1070-1080.

8. Sessler DI. Perioperative heat balance. Anesthesiology. 2000;92:578-596.

9. Jo YY, Chang YJ, Kim YB, Lee S, Kwak HJ. Effect of Preoperative Forced-Air Warming on Hypothermia in Elderly Patients Undergoing Transurethral Resection of the Prostate. Urol J. 2015;12:2366-2370.

10. Hynson JM, Sessler DI, Moayeri A, McGuire J, Schroeder $M$. The effects of preinduction warming on temperature and blood pressure during propofol/nitrous oxide anesthesia. Anesthesiology. 1993;79:219-228.

11. Andrzejowski J, Hoyle J, Eapen G, Turnbull D. Effect of prewarming on post-induction core temperature and the incidence of inadvertent perioperative hypothermia in patients undergoing general anaesthesia. $\mathrm{Br} J$ Anaesth. 2008;101:627-631.

12. Giesbrecht GG, Ducharme MB, McGuire JP. Comparison of forced-air patient warming systems for perioperative use. Anesthesiology. 1994;80:671-679.

13. Singh P, Dimitriou V, Mahajan RP, Crossley AW. Doubleblind comparison between doxapram and pethidine in the treatment of postanaesthetic shivering. $\mathrm{Br} \mathrm{J}$ Anaesth. 1993;71:685-688.

14. Palmer JB, Lane D, Mayo D, Schluchter M, Leeming R. Effects of Music Therapy on Anesthesia Requirements and Anxiety in Women Undergoing Ambulatory Breast Surgery for Cancer Diagnosis and Treatment: A Randomized Controlled Trial. J Clin Oncol. 2015;33:3162-3168.

15. Kollmann Camaiora A, Brogly N, Alsina E, de Celis I, Huercio I, Gilsanz F. Validation of the Zero-Heat-Flux thermometer (SpotOn(R)) in major gynecological surgery to monitor intraoperative core temperature: a comparative 
study with esophageal core temperature. Minerva Anestesiol. 2019;85:351-357.

16. Schnider TW, Minto CF, Shafer SL, et al. The influence of age on propofol pharmacodynamics. Anesthesiology. 1999;90:1502-1516.

17. Winkler M, Akca O, Birkenberg B, et al. Aggressive warming reduces blood loss during hip arthroplasty. Anesth Analg. 2000;91:978-984.

18. Perl T, Peichl LH, Reyntjens K, Deblaere I, Zaballos JM, Brauer A. Efficacy of a novel prewarming system in the prevention of perioperative hypothermia. A prospective, randomized, multicenter study. Minerva Anestesiol. 2014;80:436-443.

19. Bayir H, Yildiz I, Erdem F, et al. Effect of perioperative inadvertent hypothermia on the ECG parameters in patients undergoing transurethral resection. Eur Rev Med Pharmacol Sci. 2016;20:1445-1449.

20. Singh R, Asthana V, Sharma JP, Lal S. Effect of irrigation fluid temperature on core temperature and hemodynamic changes in transurethral resection of prostate under spinal anesthesia. Anesth Essays Res. 2014;8:209-215.

21. Horn EP, Bein B, Böhm R, Steinfath M, Sahili N, Höcker J. The effect of short time periods of pre-operative warming in the prevention of peri-operative hypothermia. Anaesthesia. 2012;67:612-617.

22. Darvall J, Vijayakumar R, Leslie K. Prewarming neurosurgical patients to minimize hypotension on induction of anesthesia: a randomized trial. Can J Anaesth. 2016;63:577-583.

23. Kim JY, Shinn H, Oh YJ, Hong YW, Kwak HJ, Kwak YL. The effect of skin surface warming during anesthesia preparation on preventing redistribution hypothermia in the early operative period of off-pump coronary artery bypass surgery. Eur J Cardiothorac Surg. 2006;29:343-347.

24. Alfonsi P. Postanaesthetic shivering. Epidemiology, pathophysiology and approaches to prevention and management. Minerva Anestesiol. 2003;69:438-442.

25. Allen TK, Habib AS. Inadvertent Perioperative Hypothermia Induced by Spinal Anesthesia for Cesarean Delivery Might Be More Significant Than We Think: Are We Doing Enough to Warm Our Parturients? Anesth Analg. 2018;126:7-9.

26. Frank SM, El-Rahmany HK, Cattaneo CG, Barnes RA. Predictors of hypothermia during spinal anesthesia. Anesthesiology. 2000;92:1330-1334. 